\title{
Một số giải pháp khắc phục lỗi chính tả của người sử dụng tiếng Việt
}

\author{
Phan Thị Hồng Xuân* \\ Truoòng Đại học Su phạm Hà Nội, 136 Xuân Thủy, Cầu Giấy, Hà Nội, Việt Nam \\ Nhận ngày 10 tháng 2 năm 2017 \\ Chỉnh sửa ngày 20 tháng 4 năm 2017; Chấp nhận đăng ngày 23 tháng 6 năm 2017
}

Tóm tắt: Chính tả có một vai trò quan trọng trong giao tiếp. Hiện nay, có rất nhiều người mắc lỗi chính tả. Điều đó gây ra nhiều hệ lụy. Có nhiều nguyên nhân dần tới việc viết sai chính tả. Muốn khắc phục vấn nạn này cần tìm hiểu những nguyên nhân và có những giải pháp phù hợp. Bài báo tập trung nghiên cứu vấn đề đó.

Tù̀ khóa: Lỗi, chính tả, tiếng Việt, giải pháp.

\section{1. Đặt vấn đề}

Chính tả có một vai trò quan trọng đối với mỗi cá nhân và cả cộng đồng xã hội. Vấn đề viết đúng chính tả luôn luôn được đặt ra để nâng cao hiệu quả sử dụng tiếng Việt. Tuy nhiên, đã từ lâu, vì nhiều lí do khác nhau, mắc lỗi chính tả đã trở thành một căn bệnh trầm kha của nhiều người Việt. Người lớn mắc, trẻ em mắc, người học ít mắc, người học nhiều cũng mắc. Điều đó ảnh hưởng không nhỏ tới hiệu quả giao tiếp và làm mất đi sự trong sáng của tiếng Việt. Bài báo này tìm hiểu thực trạng, phân tích tác hại, nguyên nhân, từ đó đề xuất một số giải pháp nhằm khắc phục vấn nạn này.

\section{Nội dung nghiên cứu}

Trước hết cần phải hiểu chính tả là gì. Chính tả được hiểu là "phép viết đúng" hoặc "lối viết hợp với chuẩn". Nói cách khác, chính tả là việc tiêu chuẩn hóa chữ viết của một ngôn ngữ. Yêu

\footnotetext{
ĐT.: 84-912914248.

Email: phanhongxuan@gmail.com

https://doi.org/10.25073/2588-1159/vnuer.4087
}

cầu cơ bản của chính tả là phải thống nhất cách viết cụ thể trên phạm vi toàn quốc và trong tất cả các loại hình văn bản viết... [1, 112].

Tiếp theo cần hiểu thế nào là lỗi chính tả: lỗi chính tả là lỗi viết sai chuẩn chính tả bao gồm các hiện tượng vi phạm các quy định chính tả về viết hoa, viết tắt, dùng số và biểu thị chữ số và hiện tượng vi phạm diện mạo ngữ âm của từ thể hiện trên chữ viết, tức chữ viết ghi sai từ, hay còn gọi là lỗi âm vị. Lỗi âm vị trong tiếng Việt thường thể hiện qua các dạng: lỗi âm vị âm đoạn tính và lỗi âm vị siêu âm đoạn tính. Lỗi âm vị âm đoạn tính bao gồm, lỗi sai về phụ âm đầu, âm đệm, âm chính, âm cuối. Lỗi âm vị siêu đoạn tính chính là hiện tượng viết sai thanh điệu.

\subsection{Thực trạng viết sai chính tả hiện nay}

Nhìn vào những bức ảnh dưới đây đủ thấy được lỗi viết sai chính tả diễn ra trầm trọng đến mức độ nào. Nó diễn ra trong nhà trường, ngoài xã hội, trong giao tiếp của người dân và cả những cơ quan nhà nước. Điều này ảnh hưởng rất lớn tới cuộc sống. 

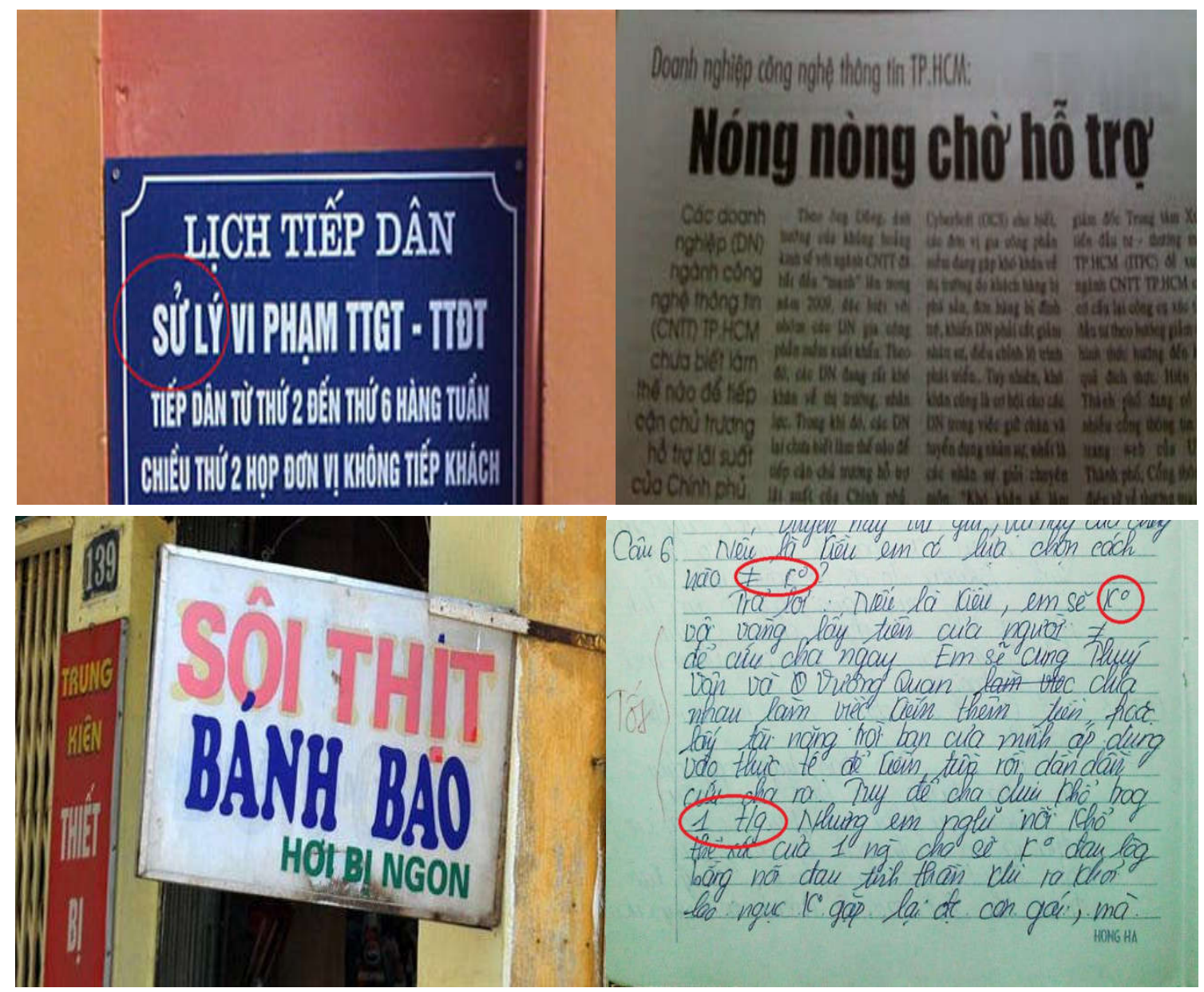

\subsection{Tác hai}

Viết sai chính tả nhiều khi dẫn tới sự hiểu lầm nội dung giao tiếp. Đối với mỗi cá nhân, việc viết sai chính tả thể hiện sự bất cập về tư duy và trình độ văn hóa của người đó. Còn đối với mỗi cơ quan, khi giấy tờ, văn bản chính thức mắc lỗi chính tả sẽ thể hiện sự thiếu chuyên nghiệp cũng như sự yếu kém về trình độ chuyên môn, văn hóa, năng lực quản lí. Điều này làm làm giảm uy tín của cơ quan và ảnh hưởng tới sự tin tưởng của người dân.

\subsection{Nguyên nhân mắc lỗi chính tả}

Có rất nhiều nguyên nhân dẫn tới thực trạng này nhưng có thể quy về một số nguyền nhân chính sau đây.
1) Thứ nhất là do không nắm vững chính tự. Ví dụ, lẽ ra phải viết là ngành thì lại viết là nghành. Điều này có nguyên nhân sâu xa từ một số bất hợp lí của chữ quốc ngữ. Sự bất hợp lí này thể hiện như sau: không đảm bảo sự tương ứng một đối một giữa âm và chữ. Chẳng hạn, âm $|k|$ có 3 cách ghi là $c, k, q$; con chữ $g$ ghi âm $|z|$ và âm $|\gamma|$. Có những nhóm hai, ba con chữ để ghi một âm vị:ph, ngh. Điều này làm người nghe lúng túng vì tại sao cùng đọc là $|\mathrm{k}|$ nhưng lúc thì viết là $c$, lúc thì viết là $k$, lúc lại viết là $q$, cùng đọc là $/ \mathrm{y} /$ mà lúc viết là $n g$ lúc lại viết là $n g h$. Đã có nhiều ý kiến đề nghị khắc phục những bất hợp lí này nhưng cho đến nay vì nhiều nguyên nhân khác nhau nó vẫn tồn tại.

2) Thứ hai là do không hiểu nghĩa. Tuy chính tả tiếng Việt là chính tả ngữ âm nhưng trên thực tế, muốn viết đúng, nhiều trường hợp 
phải nắm được ngữ nghĩa. Ví dụ: lẽ ra phải viết là giành (với nghĩa là tranh) thì lại viết là dành (với nghĩa là giữ lại để sau này dùng hoặc để riêng cho ai, cho việc gì) và ngược lại; lẽ ra phải viết là tham quan (tham là tham gia, tham dự, tìm tòi, nghiên cứu, tìm hiểu, quan là nhìn trực tiếp một cách kĩ lưỡng, tỉ mỉ, sâu sắc) thì lại viết là thăm quan; lẽ ra phải viết là khúc chiết (có nghĩa là có từng đoạn, từng ý, rành mạch và gãy gọn) thì lại viết là khúc triêt.

3) Thứ ba là do không cập nhật những quy định chính tả hiện hành. Chẳng hạn: trước đây do đề cao sự cân đối của chữ viết nên dấu thanh được đánh vào âm đứng giữa trong âm tiết. Ví dụ hoá được viết là hóa, thuý được viết là thúy. Nhưng hiện nay, với quy định dấu phải đánh vào âm chính thì cách viết như trên đã lạc hậu. Hoặc trước đây, tên cơ quan, tổ chức viết khác so với hiện nay. Ví dụ, trước đây viết là Trường đại hoc bách khoa Hà nội, còn hiện nay viết là Trường Đai hoc Bách khoa Hà Nọi. Do không cập nhật điều đó nên nhiều người đã viết theo quy định cũ dẫn đến sai chính tả.

4) Thứ tư là do ảnh hưởng của cách phát âm địa phương.

Ví dụ phương ngữ Bắc Bộ không có ba âm quặt lưỡi $|t||s ̧||z|$ vì thế nhiều người gặp khó khăn khi phải viết các từ có chứa những phụ âm đầu $c h-t r, r-d-g i, s-x$. Người nói phương ngữ Bắc Trung Bộ lại nhầm giữa dấu hỏi (?) và dấu ngã $(\sim)$. Vì thế họ rất lúng túng khi gặp những từ có dấu hỏi và dấu ngã. Họ sẽ không hiểu: viết là mâu thuẫn đúng hay mâu thuẩn đúng. Cũng như vậy, phương ngữ Nam Bộ lại có vấn đề khi viết các âm đầu là $\mathrm{v}$ hay $\mathrm{z}$, âm cuối là $n$ hay $n g, c$ hay $t$, viết dấu hỏi hay dấu ngã. Một số người sẽ rất lúng túng khi gặp những từ có chứa những phụ âm đầu, phụ âm cuối và thanh điệu này.

5) Thứ năm là do sự cẩu thả của người viết. Biểu hiện của loại lỗi do nguyên nhân này rất phong phú. Ví dụ, viết hoa không theo quy tắc nào (Nguyễn thị Kim Liên, Hải phòng). Hoặc đang viết bình thường lại viết chữ to hơn nên vô tình cũng mắc lỗi viết hoa bừa bãi (Đây là ngày thư hai tôi ở Hà Nôii.) Hoặc sau dấu chấm không viết hoa. Hoặc huờng lại viết là huờng.
6) Thứ sáu là do ảnh hưởng của ngôn ngữ mạng. Ngôn ngữ mạng phù hợp với nhu cầu muốn giao tiếp nhanh, muốn thể hiện cá tính và sự cập nhật về công nghệ hiện đại của một số người, phần lớn là giới trẻ. Tuy nhiên, trong giao tiếp có nghi thức việc sử dụng ngôn ngữ này không phù hợp và khi viết sử dụng ngôn ngữ mạng sẽ bị coi là mắc lỗi chính tả. Ví dụ cần phải viết: $a$ thì lại viết $a h$, ̀̀ thì lại viết $u h$, được thì lại viết đkk, trong thì lại viết (.)...

\subsection{Giải pháp khắc phục lỗi chính tả}

Từ việc phân tích thực trạng và nguyên nhân mắc lỗi chính tả của người sử dung tiếng Việt, chúng tôi đề xuất một số giải pháp khắc phục như sau:

2.4.1. Nhóm giải pháp đối với các cơ quan, tổ chức hữu quan

a. Giáo dục ý thức viết đúng chính tả cho người dân. Cần phải làm cho mọi người hiểu rằng viết đúng chính tả không chỉ thể hiện trình độ văn hóa mà còn thể hiện ý thức tôn trọng cộng đồng, lòng yêu quý đối với tiếng Việt của người viết. Còn viết sai chính tả ảnh hưởng nghiêm trọng tới giao tiếp của từng người dân, của toàn xã hội và rất nhiều trường hợp ảnh hưởng tới quốc gia, dân tộc. Câu chuyện sau đây cho thấy rõ điều đó. Năm 2005, Ngân hàng Quốc gia Philippines phải ra thông báo chính thức xin lỗi toàn dân vì sự cố lỗi chính tả trên tờ bạc 100 peso mới phát hành. Ở tờ bạc mới này, tển tổng thống Aroroyo đã bị viết nhầm thành Arovoyo. Việc viết sai này dù chỉ là một kí tự nhưng không chỉ ảnh hưởng đến thể diện ngoại giao mà còn gây tổn thất về kinh tế (Ngân hàng trên phải chịu toàn bộ chi phí in lại đợt giấy bạc mới và hủy toàn bộ serie in lỗi) $[5,182]$.

b. Tuyên truyền, phổ cập các chuẩn mực chính tả rộng rãi trong cộng đồng sử dụng tiếng Việt bằng các con đường khác nhau như qua các phương tiện thông tin đại chúng, qua nhà trường.

c. Duy trì các biện pháp giúp người sử dụng tiếng Việt viết đúng chính tả. Ví dụ:Văn bản của các cơ quan, tổ chứcvà văn bản trên các phương tiện thông tin đại chúng phải tuyệt đối tuân thủ các quy định về chính tả để người dân coi đó là các văn bản mẫu và làm theo; Duy trì 
mục dọn vườn trên đài truyền hình, báo chí giúp người dân nâng cao kĩ năng chính tả.

d. Có chính sách phát triển ngôn ngữ phù hợp trong bối cảnh tiếng Việt có nhiều sự biến đổi trước những biến động của thế giới. (Chẳng hạn chọn cách ứng xử phù hợp với ngôn ngữ mạng. Trong giao tiếp có nghi thức như khi làm các văn bản giấy tờ, trong học tập... không được sử dụng ngôn ngữ mạng. Giáo dục cho cá nhân ý thức rõ khi nào có thể sử dụng ngôn ngữ mạng, khi nào không được sử dụng ngôn ngữ mạng).

e. Cần có những quy định cụ thể, tiến tới ban hành luật để có chế tài xử lí đối với các trường hợp viết sai chính tả, đặc biệt là những trường hợp viết sai chính tả gây hậu quả nghiêm trọng.

2.4.2. Nhóm giải pháp đối với nhà trường

a. Đánh giá đúng vai trò, vị trí của môn chính tả trong nhà trường. Mỗi nhà giáo phải làm một tấm gương mẫu mực về việc viết đúng chính tả.

b. Có chương trình phù hợp tạo điều kiện để dạy học chính tả ở mọi nơi, mọi lúc trong mọi môn học.

c. Có nội dung dạy học chính tả hợp lí để có thể tích hợp dạy học chính tả với các kiến thức và kĩ năng khác.

d. Có phương pháp phù hợp, phát huy được tính tích cực chủ động và thu hút hấp dẫn để học sinh nắm vững chính tảngay từ cấp tiểu học và bổ sung, hoàn thiện kĩ năng viết đúng chính tả ở những cấp học tiếp theo. Ví dụ: Kết hợp dạy chính tả có ý thức với chính tả không có ý thức; tổ chức các câu lạc bộ dành cho những người yêu tiếng Việt trong nhà trường. (Các câu lạc bộ này sinh hoạt thường kì và có chuyên đề chính tả để các thành viên câu lạc bộ sẽ chia sẻ, thảo luận, học hỏi lẫn nhau các vấn đề về chính tả.

Trong những lần sinh hoạt thường kì nên tổ chức các hoạt động như:

a. Chia sẻ các quy định mới nhất về chính tả.

b. Thảo luận về các trường hợp dễ sai chính tả. Ví dụ, viết là vô hình trung, vô hình chung hay vô hình dung (cách viết đúng là: vô hình trung); viết là lên hay nên. Trường hợp này nên tham khảo ý kiến sau đây:
Nên có 3 nghĩa chính:

Chỉ quá trình biến đổi, hình thành của sự vật hiện tượng, sự thành công của con người (đồng nghĩa với thành hàm ý tích cực). Ví dụ: trở nên, nên người, nên duyên, nên khôn, nên cơm, nên cháo, xây dựng nên hình tương,...

Biểu thị sự khuyên răn (gần nghĩa với cần, phải). Ví dụ: nên nghĩ kĩ, sao nên làm vậy?

Nên được dùng để biểu đạt kết quả trong nhân quả: vì ... nên. Ví dụ: cách sông nên phải luy đò.

Lên có 5 nghĩa chính:

Chỉ sự di chuyển vị trí, dời chỗ theo hướng $d u ̛ o ̛ ́ i \rightarrow$ trên, thấp $\rightarrow$ cao, sau $\rightarrow$ truớc. Ví dụ: Học sinh lên bảng.

Đặt một vật định vị theo chiều thẳng đứng. Ví dụ: Dựng cột lên.

Biểu đạt xu hướng phát triển, tăng số lượng hoặc chất lượng, đạt mức cao hơn. Ví dụ: lên cân, lên luơng, lên chức, lên tay nghề, béo lên, đẹp lên, tốt lên, nắng vàng lên rục rõ̃.

Nói về tuổi trẻ từ 1 đến 10 . Ví dụ: Cháu bé lên năm.

Biểu thị ý động viên phải thúc giục. Ví dụ: Cố lên!, Nhanh lên! [2, 79, 80, 81, 82, 83].

Chia sẻ những trường hợp chính tả đặc biệt. Ví dụ những trường hợp được chấp nhận nhiều cách viết: dập dơn, rập rờn, giập giờn; xoong, soong; hằng ngày, hàng ngày....

Kể các câu chuyện vui về chính tả, chẳng hạn: Hai học sinh ngồi nói chuyện với nhau. Một học sinh than thở: - Cô giáo tớ cho điểm đắt quá. Cả bài văn tớ viết hay như thế, chỉ vì sai một lỗi chính tả mà cho tớ "ăn trứng". - Thế cậu viết sai chỗ nào? - Thay vì viết "cô giáo em say mê trồng người", tớ viết nhầm thành "cô giáo em say mê chồng người";

Đố vui có thưởng về chính tả, chẳng hạn:

Em là thứ bánh thường dùng

$N g \tilde{a}$ vào mưa gió, đùng đùng nổi lên

Bây giờ $n g a \tilde{a}$ bỏ, sắc thêm

Người người khiếp sợ là tên con gì

Thêm huyền em hóa vật chi

Mà người thợ mộc đôi khi thường dùng?

(bao - bão - báo - bào) [3, 45]

Thi xem ai viết đúng chính tả. Ví dụ, viết chính tả bài thơ sau: 
Xin tạm biệt đời yêu quý nhất

Còn mấy vần thơ, một nắm tro

Thơ gửi bạn đường tro bón đất

Sống là cho và chết cũng là cho.

(Tố Hữu)

2.4.3. Nhóm giải pháp đối với từng cá nhân

a. Nâng cao tri thức tiếng Việt nói riêng, tri thức bách khoa nói chung của người viết. Muốn mở rộng và nâng cao tri thức mỗi cá nhân cần phải học tập, rèn luyện một cách tích cực, thường xuyên. Điều này giúp họ:

b. Nắm vững chính tự, lúc đó thay vì viết qoăn qoeo thì sẽ viết là quăn queo.

c. Nắm được những quy tắc chính tả hiện hành. Lúc đó thay vì viết Truờng đại học su phạm Hà nọi thì sẽ viết Trường Đại học Su phạm Hà Nội.

Hiểu được chính tả tiếng Việt là chính tả ghi âm nhưng đồng thời cũng là chính tả ngữ nghĩa. Lúc đó, thay vì viết Giục tốc bất đạt thì sẽ viết Duc tốc bất đạt; thay vì viết sát nhập sẽ viết là sáp nhập; thay vì viết chín mùi sẽ viết là chín muồi; thay vì viết chuẩn đoán sẽ viết là chẩn đoán; thay vì viết nhận chức sẽ viết là nhậm chưc.

d. Sử dụng mẹo chính tả. Mẹo chính tả được trình bày trong rất nhiều tài liệu. Ví dụ: Trong Sổ tay chính tả tiếng Việt tiểu hoc, tác giả Nguyễn Đình Cao đã đưa ra một số mẹo sau đây:

Mẹo phân biệt ch/tr: Ví dụ: Mẹo trừng trị. Mẹo này như sau: Tiếng Hán Việt mang một trong ba dấu: huyền, ngã, nặng thì phụ âm đầu chỉ viết tr.

Trà, tràng, trào, trầm, trần, trì, triều, trình, trù, trùng, trừ, truyền (12 chữ mang dấu huyền); trĩ, trữ ( 2 chữ mang dấu ngã); trạch, trại, trạm, trạng, trận, trập, trệ, trị, triện, triệt, triệu, trịnh, trọc, trọng, trợ, trụ, trục, trụy, truyện, trực, trượng (21 chữ mang dấu nặng) [2, 33].

Mẹo phân biệt d/gi: Ví dụ: Gặp một chữ có phần vần bắt đầu bằng $o a, o a ̆, u \hat{a}, u y$, uyê thì âm đầu chỉ được viết là $d$, không được viết là $g i$ hay $r[2,45]$.

Mẹo phân biệt 1/n: Ví dụ: $N$ kết hợp với âm đệm rất hạn chế, chỉ trong vài ba từ Hán Việt như: noa (trẻ con), thê noa (vợ con), noãn (trứng), noãn sào (buồng trứng). Còn lại, những vần chứa âm đệm chỉ kết hợp với $L$ : cái loa, lòa xòa, quần loe, loắt choắt, luẩn quẩn, luật pháp, luân lí, lũy tre, luyện tập,... [2, 83, 84]

Mẹo phân biệt $\mathrm{s} / \mathrm{x}$ : Ví dụ: Những từ có nghĩa là sụp xuống, giảm sút viết với $S$

Sã cánh, sa sẩy, sỉa chân, sa sút, sà thấp, sạt lở, đổ sập, sệ xuống, sọm đi, suy sụp, sụm sụt...[2, 104]

Còn rất nhiều mẹo nữa mà việc nhớ những mẹo này sẽ khắc phục được lỗi chính tả cho người viết.

e. Nhớ từng trường hợp. Trong tiếng Việt có những trường hợp chính tả không nằm bền trong cấu trúc hệ thống chính tả tiếng Việt do cách phát âm địa phương hoặc các nguyên nhân lịch sử gây ra. Ví dụ những người thuộc phương ngữ Bắc Bộ thường phát âm lẫn lộn $S$ với $X, T R$ với $C H, D$ với $G I, R \ldots$ Đối với những trường hợp này cần phải nhớ kĩ, nhớ máy móc từng trường hợp cụ thể kết hợp với việc suy xét cụ thể mới có thể viết đúng. Ví dụ: giâu gia, hoa giẻ, rau sắng, xẻ gỗ (xẻ thường đi với bổ ngữ có tính chất cụ thể), chia sẻ (sẻ thường đi với bổ ngữ có tính chất trừu tượng), truyện ngắn (truyện gắn với viết), kể chuyện (chuyện gắn với nói). Nhà nghiên cứu Nguyễn Như Ý đã viết: "Muốn viết đúng chính tả tiếng Việt, trước hết phải học nhiều năm trong nhà trường để nắm chắc quy tắc chính tả tiếng Việt, đồng thời phải thường xuyên rèn tập trong thực tế viết lách để biết cách viết đúng các trường hợp chính tả "bất quy tắc" mà chỉ có thể bằng kinh nghiệm hoặc nhớ thuộc lòng, thành thói quen mới viết đúng được" $[4,3]$.

g. Sử dụng sổ tay chính tả, từ điển, sự trợ giúp của máy tính. Trong nhiều trường hợp, phải dùng sổ tay chính tả; dùng từ điển và sự trợ giúp của máy tính. Tuy nhiên, sau đó cần ghi nhớ để khi không có sự trợ giúp của những phương tiện này vẫn viết đúng chính tả.

h. Sử dụng sổ tay chính tả cá nhân. Sổ tay ghi chép những trường hợp hay sai, những trường hợp đặc biệt như khúc chiết, xán lạn, giăt gịa, khuếch trương, tuềnh toàng; sổ tay còn ghi những bài thơ, câu văn giúp viết đúng chính tả. Ví dụ: 
Gặp tù̀ Hán Việt khó thay

Bạn ơ nhớ lấy câu này mà ghi

Già giang giảm giá "giê $+i$ " (gi)

Di dân, duỡng duc "dê đê" (d) chớ lầm.

Chị em bà con ruột rà thuoong quý nhau da diết.

Ho ráng sức ra công, hoàn thành nhanh số hàng gia công.

Hôm nay có xúp, có xôi lạp xường, có thịt xá xíu, có bún xáo nóng sốt, mời cậu sinh viên xơ tam.

i. Tập phát âm cho đúng. Chính tả tiếng Việt là chính tả ngữ âm theo phương châm nghe nhu thế nào viết thế ấy. Tuy nhiên, do có nhiều phương ngữ, thổ ngữ nên trên thực tế không thể theo phương châm này được. Đại đa số người Việt tuy phát âm không đúng với chuẩn chính âm, nhưng vẫn viết đúng chính tả. Bên cạnh đó, một số người, do ảnh hưởng của phát âm địa phương và nhận thức còn hạn chế nên nói như thế nào thì viết như thế dẫn đến sai chính tả. Ví dụ, vì không phân biệt dấu hỏi và dấu ngã và không hiểu nghĩa của từ, nên lẽ ra phải viết tình mẫu tử thì lại viết là tình mẩu tử. Trường hợp này thường rơi vào những người có trình độ học vấn thấp. Với những người này, phát âm đúng sẽ góp phần giúp cho họ viết chính tả đúng. Tuy nhiên, đây không thể coi là một giải pháp chính mà chỉ nên coi là giải pháp bổ trợ vì không thể cứ chờ phát âm đúng mới viết đúng chính tả.

$\mathrm{k}$. Rèn luyện tính cẩn thận. Người viết cần có ý thức rèn luyện tính cẩn thận. Có nghĩa là suy nghĩ cẩn trọng trước khi viết, không viết bừa, viết ẩu, cố gắng viết đúng ngay từ lần đầu tiên, khi viết xong cần đọc lại thật kĩ, nếu phát hiện lỗi thì khắc phục kịp thời.

Cho dù có giải pháp nào đi nữa thì điều quan trọng là mỗi cá nhân cần có ý thức rèn luyện chính tả ở mọi lúc, trong mọi hoạt động có liên quan tới việc sử dụng ngôn ngữ, làm cho việc viết đúng chính tả trở thành một phản xạ tự nhiên. Có như vậy mới góp phần viết đúng, khắc phục được vấn nạn viết sai chính tả hiện nay.

\section{Kết luận}

Trong những năm gần đây, do dân trí được nâng cao, vấn đề viết đúng chính tả khi giao tiếp trong nhà trường và trong cộng đồng đã có những cải thiện. Tuy nhiên, mắc lỗi chính tả là một vấn đề nổi cộm và không thể khắc phục trong một sớm, một chiều. Có rất nhiều giải pháp được đặt ra. Trong những giải pháp đó, quan trọng nhất là giáo dục ý thức và nâng cao trình độ tiếng Việt cho người sử dụng. Khi thấy rõ tầm quan trọng của vấn đề, người sử dụng sẽ tự học hỏi để nâng cao trình độ tiếng Việt và khắc phục tình trạng viết sai chính tả.

Bên cạnh đó, cũng cần có sự vào cuộc của các nhà khoa học, các nhà giáo dục, các cơ quan, ban, ngành, thậm chí cần có những giải pháp kiên quyết xử lí những trường hợp viết sai chính tả làm ảnh hưởng tới uy tín của cá nhân, của cơ quan, tổ chức và vị thế quốc gia, dân tộc.

Tất cả chúng ta cần chung tay bảo vệ và giữ gìn sự trong sáng của tiếng Việt, làm cho tiểng Việt ngày càng giàu đẹp.

\section{Tài liệu tham khảo}

[1] Lê A, Đỗ Xuân Thảo, Lê Hữu Tỉnh, Giáo trình tiếng Việt 2, NXB Đại học Sư phạm, 2014.

[2] Nguyễn Đình Cao, Sổ tay chính tả tiếng Việt Tiểu học, NXB Giáo dục, 2011.

[3] Nguyễn Văn Tứ, Chuyện vui chữ nghĩa, Nxb Văn hóa-Thông tin Hà Nội, 1996.

[4] Nguyễn Như Ý, Từ điển Chính tả học sinh, NXB Giáo dục Việt Nam, 2014.

[5] Hoàng Thị Châu, Phương ngữ học tiếng Việt, NXB Đại học Quốc gia, 2004.

[6] Lê Phương Nga (chủ biên), Lê A, Đặng Kim Nga, Đỗ Kim Thảo, Phương pháp dạy học tiếng Việt ở tiểu học I, NXB Đại học Sư phạm, 2015.

[7] VIETLEX Trung tâm Từ điển học, Từ điển tiếng Việt, NXB Đà Nẵng, 2014. 


\title{
Solutions to Spelling Mistakes in Written Vietnamese
}

\author{
Phan Thi Hong Xuan \\ Hanoi National University of Education, 136 Xuan Thuy, Cau Giay, Hanoi, Vietnam
}

\begin{abstract}
Spelling plays an important role in written communication. The fact that a lot of spelling mistakes have been more frequently made causes commuinication inconveniences. This article investigates the causes of mistakes to find out appropriate solutions to the identified spelling problems.
\end{abstract}

Keywords: Mistake, spelling, Vietnamese, solution. 